\title{
An unusual case of life-threatening hemoperitoneum after colonoscopy
}

A 59-year-old man was hospitalized with acid reflux and diarrhea. Colonoscopy was performed while the patient was under propofol anesthesia, and no abnormalities were observed. However, at 3.5 hours following the colonoscopy, the patient had persistent dull pain in the lower abdomen. Physical examination indicated abdominal tenderness and rebound tenderness. The results of a digital rectal examination were unremarkable. Blood tests revealed a decreased hemoglobin level of $101 \mathrm{~g} / \mathrm{L}$. Plain radiography of the abdomen revealed no subphrenic free gas ( $\bullet$ Fig. 1 ).

Subsequently, the patient fasted and was administered ceftizoxime; however, the pain persisted. Computed tomography showed an accumulation of free fluid in the abdominal and pelvic cavities with a density level suggestive of blood, without signs of perforation or splenic injury ( $\bullet$ Fig. 2). The patient's hemoglobin level decreased further to $96 \mathrm{~g} / \mathrm{L}$, and his blood pressure was 95/65 $\mathrm{mmHg}$.

A diagnostic abdominal paracentesis was performed, which revealed noncoagulating bloody liquid. A laparoscopic exploration was then initiated, which revealed a massive amount of blood $(\sim 1500 \mathrm{~mL})$ in the abdominal cavity and a $2-\mathrm{cm}$ seromuscular laceration with attached blood clots on the anterior wall of the sigmoid colon. The liver and spleen were normal. Subsequently, the laceration was successfully repaired under the laparoscope. During a 2-year follow-up, the patient's general condition was normal, and he experienced no discomfort.

The most common complications of colonoscopy are hemorrhage and perforation [1]. Hemoperitoneum is a rare complication that is attributable mostly to splenic injury [2]. To our best knowledge, no similar cases of life-threatening hemoperitoneum caused by colonic seromus-

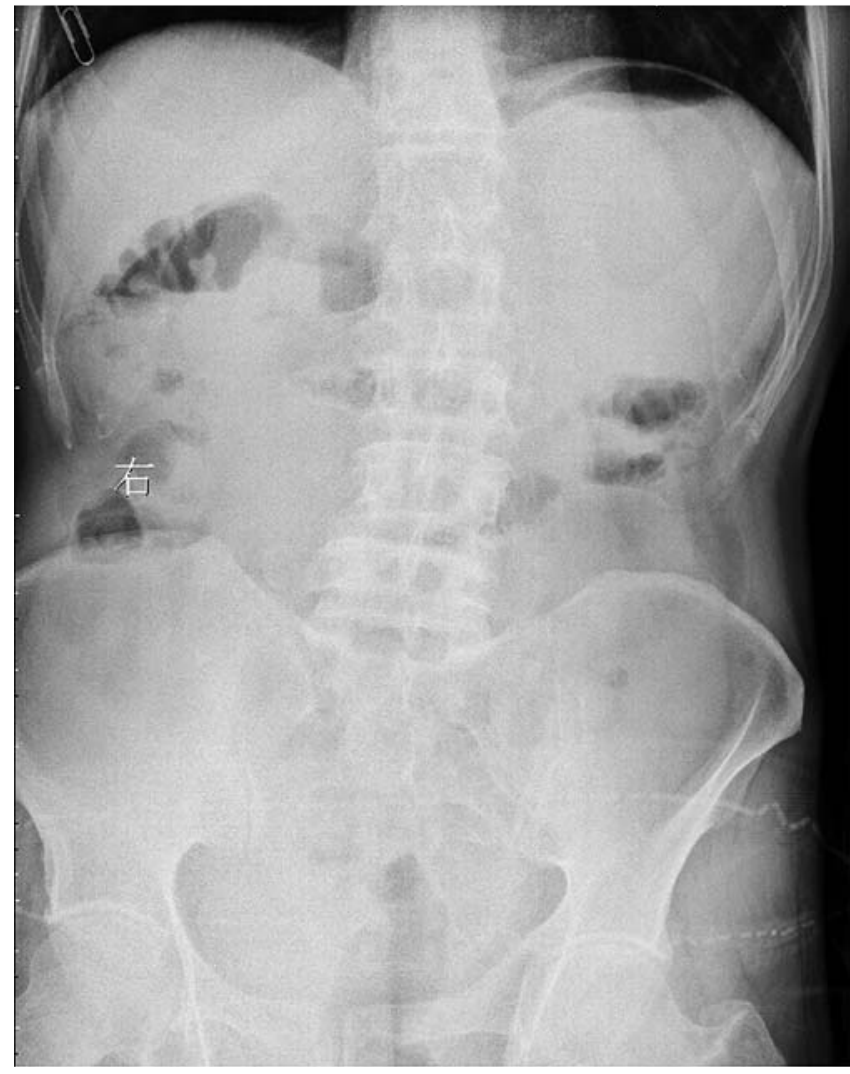

Fig. 1 In a 59-year-old man hospitalized with acid reflux and diarrhea, a plain radiograph of the abdomen obtained 3.5 hours after colonoscopy shows no subphrenic free gas, indicating the absence of pneumoperitoneum.

cular laceration after colonoscopy have been reported. Seromuscular laceration without accompanying colonic rupture is an extremely rare complication that can probably be attributed to the pressure of the air introduced through the colonoscope and stretching of the colon wall [3, 4]. Therefore, hemoperitoneum due to seromuscular laceration should be considered after the exclusion of perforation in a patient with persistent abdominal pain following colonoscopy.

Endoscopy_UCTN_Code_CPL_1AJ_2AB

Competing interests: None
Zhen Zhu ${ }^{1,}$ *, Jian Yin ${ }^{1, *}$, Haihang Zhu ${ }^{1}$, Hailong Cao ${ }^{2}$

${ }^{1}$ Department of Gastroenterology, Subei People's Hospital, Medical School of Yangzhou University, China

${ }^{2}$ Department of Gastroenterology and Hepatology, General Hospital, Tianjin Medical University, China 


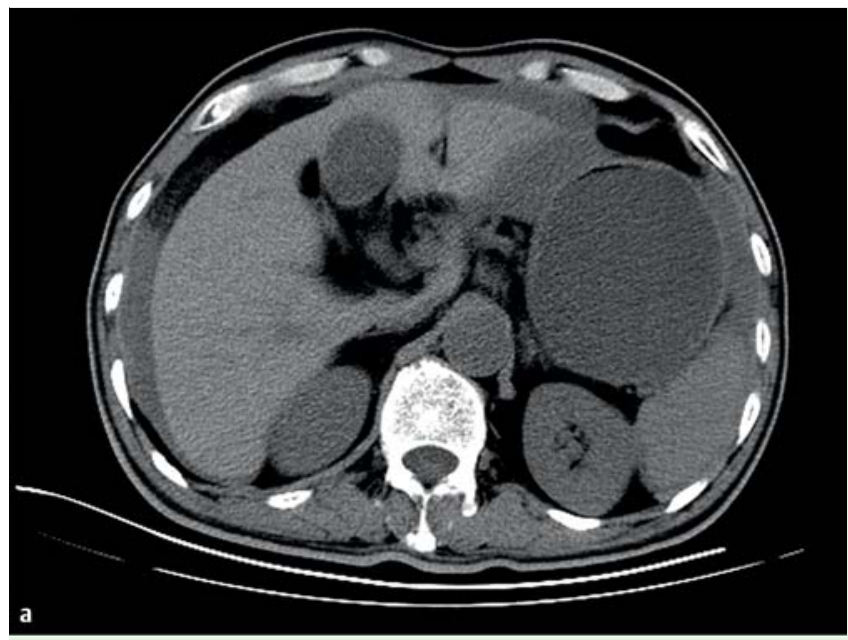

Fig. 2 Computed tomography of the whole abdomen at 10 hours after colonoscopy reveals an accumulation of free fluid whose density measurements are compatible with those of blood. There is no evidence of splenic injury, indicating that the hemoperitoneum was not induced by splenic rupture. a Abdominal cavity. b Pelvic cavity.

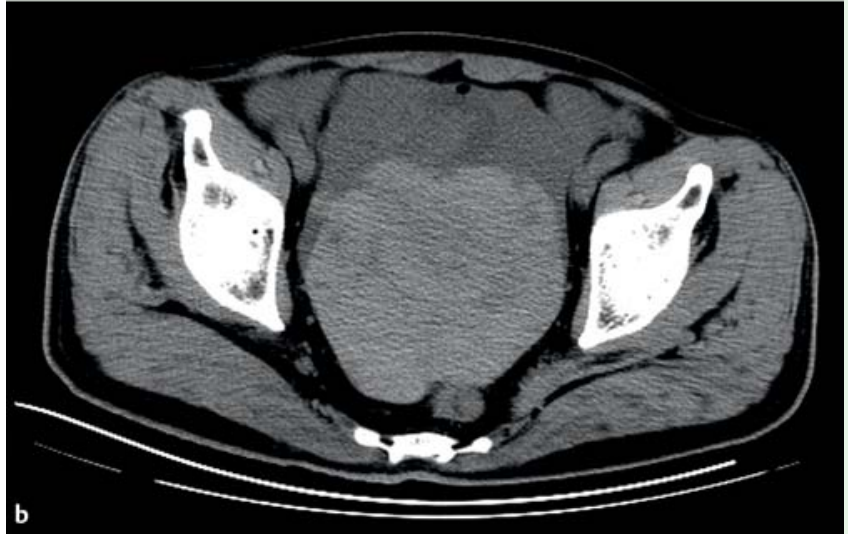

\section{Acknowledgment}

$\nabla$

This study was supported by a grant (81300272 to H.C.) from the National Natural Science Foundation of China and a grant (13JCQNJC10600 to H.C.) from the Tianjin Research Program of the Application Foundation and Advanced Technology of China.

\section{References}

1 Crispin A, Birkner B, Munte A et al. Process quality and incidence of acute complications in a series of more than 230,000 outpatient colonoscopies. Endoscopy 2009; 41: 1018 1025

2 Janes SE, Cowan IA, Dijkstra B. A life threatening complication after colonoscopy. BM] 2005; 330: 889-890

3 Uno Y, Morita T. Colonic perforation and serosal tears associated with colonoscopy. Lancet 1997; 349: 1888

4 Alcaide N, Diez-Redondo P, Herranz-Bachiller $M T$ et al. Serosal lacerations during colonoscopy - a rare complication. Endoscopy 2012; 44 (Suppl. 02): E268

\section{Bibliography}

DOI http://dx.doi.org|

10.1055/s-0034-1392972

Endoscopy 2015; 47: E468-E469

(c) Georg Thieme Verlag KG

Stuttgart · New York

ISSN 0013-726X

\section{Corresponding author}

Hailong Cao, MD

Department of Gastroenterology and Hepatology General Hospital

Tianjin Medical University

Heping District

154 Anshan Road

Tianjin 300052

China

Fax: +86-022-27813550

cao_hailong@163.com 